\title{
Application of the Method of Coordinate Grids for Experimental Study of Pipe Extrusion Process With Lateral Metal Flow
}

\author{
Kosmatskiy Yaroslav Igorevich ${ }^{1}$, Al-Jumaili Mohammed Jasim Mohammed ${ }^{1}$ \\ \& Al-Khuzaie Ahmed Saleem Oleiwi ${ }^{1}$
}

${ }^{1}$ Department of Metal Forming Processes and Machines, Federal State Autonomous Educational Institution of Higher Education, South Ural State University (national research university) (FSAEIHE SUSU (NRU)), Russia

Correspondence: Kosmatskiy Yaroslav Igorevich, Department of Metal Forming Processes and Machines, Federal State Autonomous Educational Institution of Higher Education, South Ural State University (national research university) (FSAEIHE SUSU (NRU)), Russia. E-mail: kosmatski@rosniti.ru

\author{
Received: May 12, 2017 \\ Accepted: June 16, 2017 \\ Online Published: June 30, 2018 \\ doi:10.5539/jmsr.v7n3p49 \\ URL: https://doi.org/10.5539/jmsr.v7n3p49
}

\begin{abstract}
The paper presents the results of an experimental study of pipe extrusion process with lateral flow using the method of coordinate grids. The calculation of the forming operation is made for extrusion process stages.

Keywords: pipe extrusion with lateral flow, method of coordinate grids (MCG), metal flow picture, metal forming

\section{Introduction}

As shown in Kosmatskiy and Fokin (2015) and Kosmatskiy (2016), in the mathematical modeling of pipe extrusion process with lateral flow the nature of metal flow is determined by a number of factors that distinguish this variety of pressing process from the known process of direct extrusion of pipes. In this case, the effect of these factors determines the structure of the simulated system, the properties of its elements and the cause-and-effect relationships that are inherent in the system and essential for achieving the goal of simulation (Vydrin, 1959). One of the significant factors is the position and shape of the boundaries of the plastic strain zone (Perlin, 1964; Prozorov, 1969; Thomsen, Yang, \& Kobayashi, 1969), the determination of which is a very non-trivial task.

Thus, in order to determine the zones of strain figure, the experimental study of the pipe extrusion process with lateral flow with the use of the method of coordinate grids (MCG) (Kargin \& Kargin, 2011; Del \& Novikov, 1979) may be of scientific interest. The obtained results can be applied to the adaptation of the developed mathematical models (Kosmatskiy \& Fokin, 2015; Kosmatskiy, 2016; Kosmatskiy, 2016) combined with pressing processes (Kosmatskiy, Vydrin, \& Khramkov, n.d.a; Kosmatskiy, Vydrin, \& Khramkov, n.d.b; Kosmatskiy, Khramkov, \& Fokin, 2013). At the same time, evaluating the practical value of the result, it can be assumed that the determination of the zones of distribution of plastic strain in the billet will also allow us to estimate implicitly the structure and uneven distribution of mechanical properties along the length and cross-section of the pipe (Perlin, 1964).
\end{abstract}

\section{Method}

In order to carry out an experimental study of the pipe extrusion process with metal lateral flow, the corresponding installation shown in Figure 1 was designed for the use on a press of vertical construction with a maximum force of $1.25 \mathrm{MN}$.

Preparation of sample billets with a diameter of $45 \mathrm{~mm}$ and a height of $95 \mathrm{~mm}$ with a through side hole $10 \mathrm{~mm}$ in diameter intended for carrying out an experimental study of the sample pipe extrusion process with lateral flow $30 \times 10 \mathrm{~mm}$ in size using the MCG (Kargin \& Kargin, 2011; Del \& Novikov, 1979) was carried out in accordance with the method presented in the paper (Kosmatskiy, 2016). The coordinate grid of the sample billet, shown in Figure 2, $a$, is represented by square cells with $\sim 5 \mathrm{~mm}$ side.

In order to shorten the time interval, and thus to increase the reliability of the experimental data used for the quantitative evaluation of the deformed state, in contrast to the investigation of direct extrusion of pipes (Kosmatskiy, 2016), two positions of the grid (see Tables 1 to 3), corresponding to the known phases (Perlin, 1964; Prozorov, 1969) of the pressing process were evaluated in the case under consideration. They are: pressing-out (see Figure 2, $b$ ) and steady-state phase (see Figure 3). 


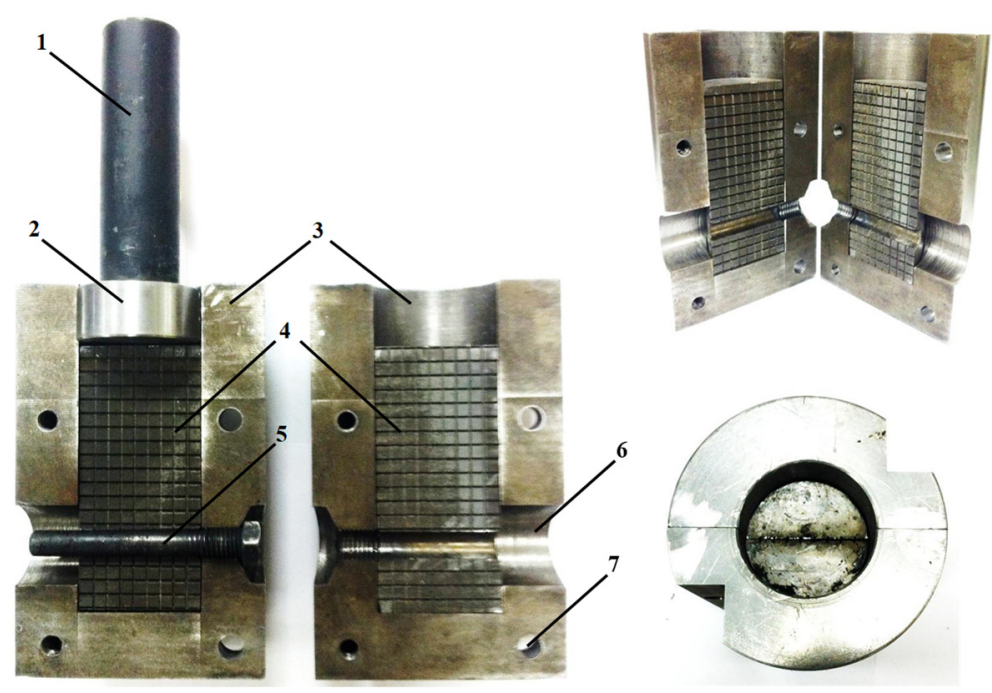

Figure 1. Segmented sizing tool accessories needed for the excremental study of extrusion process of pipes $30 \times 10 \mathrm{~mm}$ in size with lateral flow of lead $\mathrm{C} 1$ :

1 - compression ram; 2 - pressure pad; 3 - prefabricated container; 4 - billet; 5 - mandrel; 6 - die hole; 7 - prefabricated container holes (4 pieces)

\section{Results}

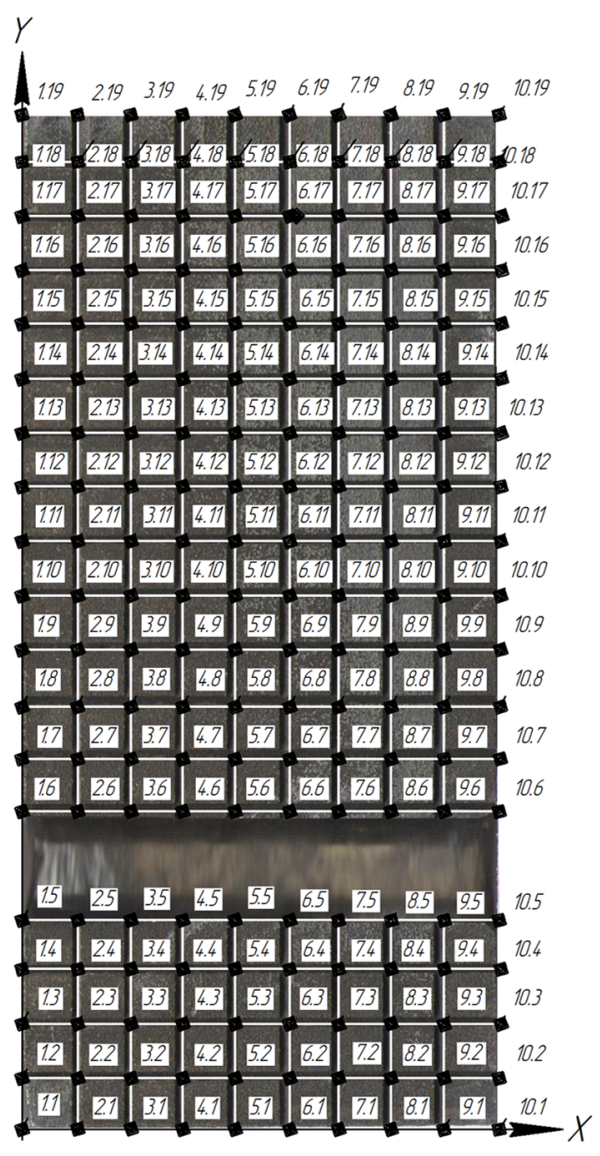

(a)

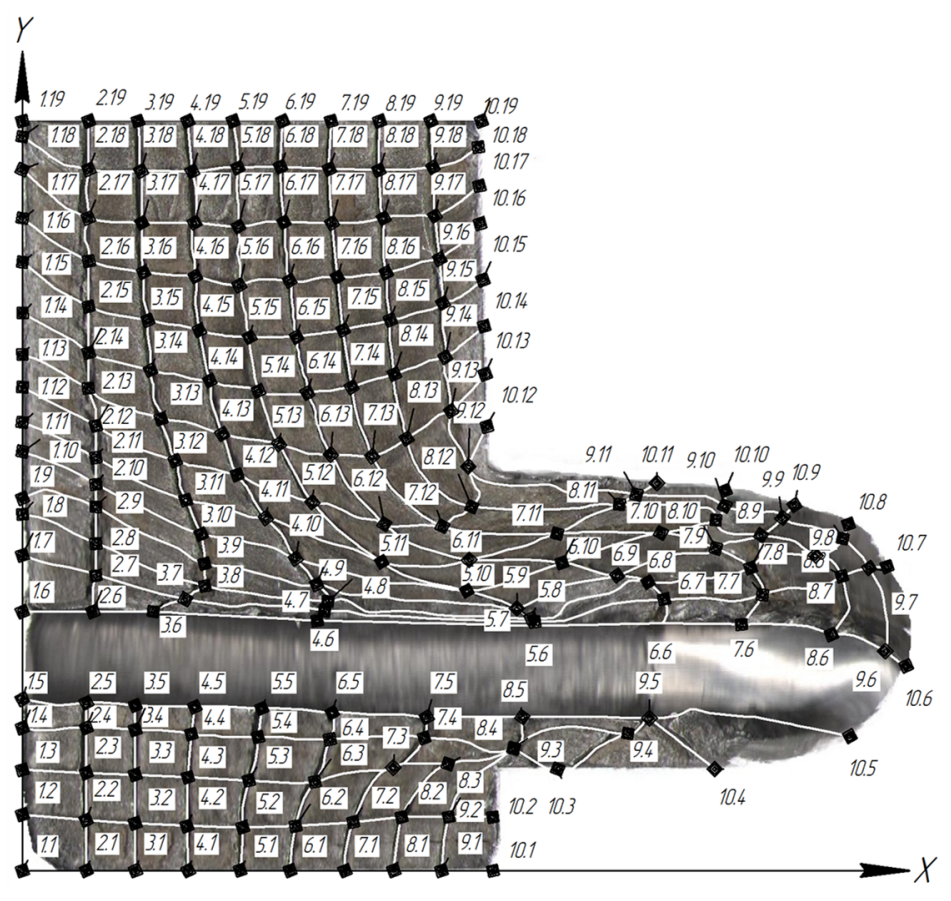

(b)

Figure 2. Sample billet with coordinate grid: (a) - before extrusion; (b) - after pressing-out in the container 
Table 1. Coordinates of the grid points of sample billet: point number (x; y), mm (see Figure $2, a$ )

\begin{tabular}{|c|c|c|c|c|c|c|c|c|c|}
\hline $1.1(0 ; 0)$ & $2.1(5 ; 0)$ & $3.1(10 ; 0)$ & $4.1(15 ; 0)$ & $5.1(20 ; 0)$ & $6.1(25 ; 0)$ & $7.1(30 ; 0)$ & $8.1(35 ; 0)$ & $9.1(40 ; 0)$ & $10.1(45 ; 0)$ \\
\hline $1.2(0 ; 5)$ & $2.2(5 ; 5)$ & $3.2(10 ; 5)$ & $4.2(15 ; 5)$ & $5.2(20 ; 5)$ & $6.2(25 ; 5)$ & $7.2(30 ; 5)$ & $8.2(35 ; 5)$ & $9.2(40 ; 5)$ & $10.2(45 ; 5)$ \\
\hline $1.3(0 ; 10)$ & $2.3(5 ; 10)$ & $3.3(10 ; 10)$ & $4.3(15 ; 10)$ & $5.3(20 ; 10)$ & $6.3(25 ; 10)$ & $7.3(30 ; 10)$ & $8.3(35 ; 10)$ & $9.3(40 ; 10)$ & $10.3(45 ; 10)$ \\
\hline $1.4(0 ; 15)$ & $2.4(5 ; 15)$ & $3.4(10 ; 15)$ & $4.4(15 ; 15)$ & $5.4(20 ; 15)$ & $6.4(25 ; 15)$ & $7.4(30 ; 15)$ & $8.4(35 ; 15)$ & $9.4(40 ; 15)$ & $10.4(45 ; 15)$ \\
\hline $1.5(0 ; 20)$ & $2.5(5 ; 20)$ & $3.5(10 ; 20)$ & $4.5(15 ; 20)$ & $5.5(20 ; 20)$ & $6.5(25 ; 20)$ & $7.5(30 ; 20)$ & $8.5(35 ; 20)$ & $9.5(40 ; 20)$ & $10.5(45 ; 20)$ \\
\hline $1.6(0 ; 30)$ & $2.6(5 ; 30)$ & $3.6(10 ; 30)$ & $4.6(15 ; 30)$ & $5.6(20 ; 30)$ & $6.6(25 ; 30)$ & $7.6(30 ; 30)$ & $8.6(35 ; 30)$ & $9.6(40 ; 30)$ & $10.6(45 ; 30)$ \\
\hline $1.7(0 ; 35)$ & $2.7(5 ; 35)$ & $3.7(10 ; 35)$ & $4.7(15 ; 35)$ & $5.7(20 ; 35)$ & $6.7(25 ; 35)$ & $7.7(30 ; 35)$ & $8.7(35 ; 35)$ & $9.7(40 ; 35)$ & $10.7(45 ; 35)$ \\
\hline $1.8(0 ; 40)$ & $2.8(5 ; 40)$ & $3.8(10 ; 40)$ & $4.8(15 ; 40)$ & $5.8(20 ; 40)$ & $6.8(25 ; 40)$ & $7.8(30 ; 40)$ & $8.8(35 ; 40)$ & $9.8(40 ; 40)$ & $10.8(45 ; 40)$ \\
\hline $1.9(0 ; 45)$ & $2.9(5 ; 45)$ & $3.9(10 ; 45)$ & $4.9(15 ; 45)$ & $5.9(20 ; 45)$ & $6.9(25 ; 45)$ & $7.9(30 ; 45)$ & $8.9(35 ; 45)$ & $9.9(40 ; 45)$ & $10.9(45 ; 45)$ \\
\hline $1.10(0 ; 50)$ & $2.10(5 ; 50)$ & $3.10(10 ; 50)$ & $4.10(15 ; 50)$ & $5.10(20 ; 50)$ & $6.10(25 ; 50)$ & $7.10(30 ; 50)$ & $8.10(35 ; 50)$ & $9.10(40 ; 50)$ & $10.10(45 ; 50)$ \\
\hline $1.11(0 ; 55)$ & $2.11(5 ; 55)$ & $3.11(10 ; 55)$ & $4.11(15 ; 55)$ & $5.11(20 ; 55)$ & $6.11(25 ; 55)$ & $7.11(30 ; 55)$ & $8.11(35 ; 55)$ & $9.11(40 ; 55)$ & $10.11(45 ; 55)$ \\
\hline $1.12(0 ; 60)$ & $2.12(5 ; 60)$ & $3.12(10 ; 60)$ & $4.12(15 ; 60)$ & $5.12(20 ; 60)$ & $6.12(25 ; 60)$ & $7.12(30 ; 60)$ & $8.12(35 ; 60)$ & $9.12(40 ; 60)$ & $10.12(45 ; 60)$ \\
\hline $1.13(0 ; 65)$ & $2.13(5 ; 65)$ & $3.13(10 ; 65)$ & $4.13(15 ; 65)$ & $5.13(20 ; 65)$ & $6.13(25 ; 65)$ & $7.13(30 ; 65)$ & $8.13(35 ; 65)$ & $9.13(40 ; 65)$ & $10.13(45 ; 65)$ \\
\hline $1.14(0 ; 70)$ & $2.14(5 ; 70)$ & $3.14(10 ; 70)$ & $4.14(15 ; 70)$ & $5.14(20 ; 70)$ & $6.14(25 ; 70)$ & $7.14(30 ; 70)$ & $8.14(35 ; 70)$ & $9.14(40 ; 70)$ & $10.14(45 ; 70)$ \\
\hline $1.15(0 ; 75)$ & $2.15(5 ; 75)$ & $3.15(10 ; 75)$ & $4.15(15 ; 75)$ & $5.15(20 ; 75)$ & $6.15(25 ; 75)$ & $7.15(30 ; 75)$ & $8.15(35 ; 75)$ & $9.15(40 ; 75)$ & $10.15(45 ; 75)$ \\
\hline $1.16(0 ; 80)$ & $2.16(5 ; 80)$ & $3.16(10 ; 80)$ & $4.16(15 ; 80)$ & $5.16(20 ; 80)$ & $6.16(25 ; 80)$ & $7.16(30 ; 80)$ & $8.16(35 ; 80)$ & $9.16(40 ; 80)$ & $10.16(45 ; 80)$ \\
\hline $1.17(0 ; 85)$ & $2.17(5 ; 85)$ & $3.17(10 ; 85)$ & $4.17(15 ; 85)$ & $5.17(20 ; 85)$ & $6.17(25 ; 85)$ & $7.17(30 ; 85)$ & $8.17(35 ; 85)$ & $9.17(40 ; 85)$ & $10.17(45 ; 85)$ \\
\hline $1.18(0 ; 90)$ & $2.18(5 ; 90)$ & $3.18(10 ; 90)$ & $4.18(15 ; 90)$ & $5.18(20 ; 90)$ & $6.18(25 ; 90)$ & $7.18(30 ; 90)$ & $8.18(35 ; 90)$ & $9.18(40 ; 90)$ & $10.18(45 ; 90)$ \\
\hline $1.19(0 ; 95)$ & $2.19(5 ; 95)$ & $3.19(10 ; 95)$ & $4.19(15 ; 95)$ & $5.19(20 ; 95)$ & $6.19(25 ; 95)$ & $7.19(30 ; 95)$ & $8.19(35 ; 95)$ & $9.19(40 ; 95)$ & $10.19(45 ; 95)$ \\
\hline
\end{tabular}

Table 2. Coordinates of the grid points of sample billet after pressing-out: point number (x;y), mm (see Figure 2, b)

\begin{tabular}{|c|c|c|c|c|c|c|c|c|c|}
\hline 0) & ) & ) & $(1,0,0,0)$ & 0) & 0) & 0) & 0) & $1(40$ & 0) \\
\hline$(0$ & & 4) & 8) & 8) & 6) & 35 & $3(40$, & 66) & 10.3( \\
\hline $1.5(0 ; 16,33)$ & $2.5(6,12 ; 16,0)$ & $3.5(10,8 ; 15,73)$ & (1) & $(22,5)$ & 4) & 62) & 6) & $9.5(60,0 ; 14,5)$ & 8) \\
\hline$(0 ; 24,66)$ & $(6,74 ; 24,66)$ & $3.6(1$ & $(28$ & $6(49$ & 3) & 7.6 & 8.6 & ,9) & 10.6 \\
\hline $1.8(0 ;$ & $\theta 0$ & $3.8(17,45 ; 27,1)$ & - & $0=0.00$ & $6.8(59,83 ; 27$ & $78,6067.20$ & $8.8(75,9 ; 30,0)$ & $9.8(78,5 ; 31,6)$ & 0) \\
\hline $1.9(0 ; 35,46)$ & $9(7,03 ; 34,64)$ & $3.9(17,4$ & $.9(28,16 ; 2$ & $5.9(4$ & 9) & $7.9(66,35$; & 9( & $9.9(7$ & 10.9 \\
\hline$-x_{0}+2$ & $2.10(7,03 ; 36,8)$ & ? & (3) & 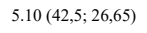 & $6.10(51,62 ; 29,3)$ & 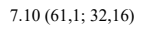 & $8.10(66,33 ; 33,4)$ & t & , \\
\hline $1.11(0 ; 42,68)$ & $.11(7,03 ; 39,32)$ & $.11(15,6 ; 35,27)$ & $4.11(23,29 ; 33,6)$ & $5.11(34,36 ; 29,4)$ & $6.11(42,73 ; 29,6)$ & $7.11(51,15 ; 32,1)$ & 811570.3480 & $9.11(58,76 ; 35,8)$ & $10.11(60,7 ; 36,9)$ \\
\hline $1.12(0 ; 46,03)$ & $12(7,03 ; 42,35)$ & $12(14,6 ; 39,02)$ & $4.12(20,56 ; 37,7)$ & $5.12(27,72 ; 35,1)$ & $6.12(34,64 ; 33,0)$ & $7.12(40,18 ; 32,8)$ & $8.12(43,0 ; 34,64)$ & $9.12(42,66 ; 38,5)$ & $10.12(44,4 ; 42,3)$ \\
\hline $6(0.6251)$ & $1646.36 .5805)$ & $165(158.570$ & 160653.560 & $5.16(20,74 ; 55,7)$ & $6.16(25,56 ; 56,2)$ & $7.16(30,12 ; 56,5)$ & 8164248.560 & $.16(39,9 ; 58,25)$ & $1016(438.61$ \\
\hline 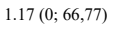 & 7( & 7) & 7) & 5 . & 6.17 & $17(29,6$ & $8.17(3$ & $9.17(39,45 ; 62,4)$ & 10.17 \\
\hline $1.18(0$ & $2.18(6$, & $6,6)$ & ;66,6) & 5 & 6 & 7 & $8.18(3$ & 0) & 10. \\
\hline 1. & $19(6,35 ; 71,37)$ & $19(11,1 ; 71,37)$ & $4.19(15,8 ; 71,37)$ & $5.19(20,2 ; 71,37)$ & $6.19(24,9 ; 71,37)$ & $7.19(29,5 ; 71,37)$ & $8.19(34,2 ; 71,37)$ & $9.19(39,1 ; 71,37)$ & 10 \\
\hline
\end{tabular}




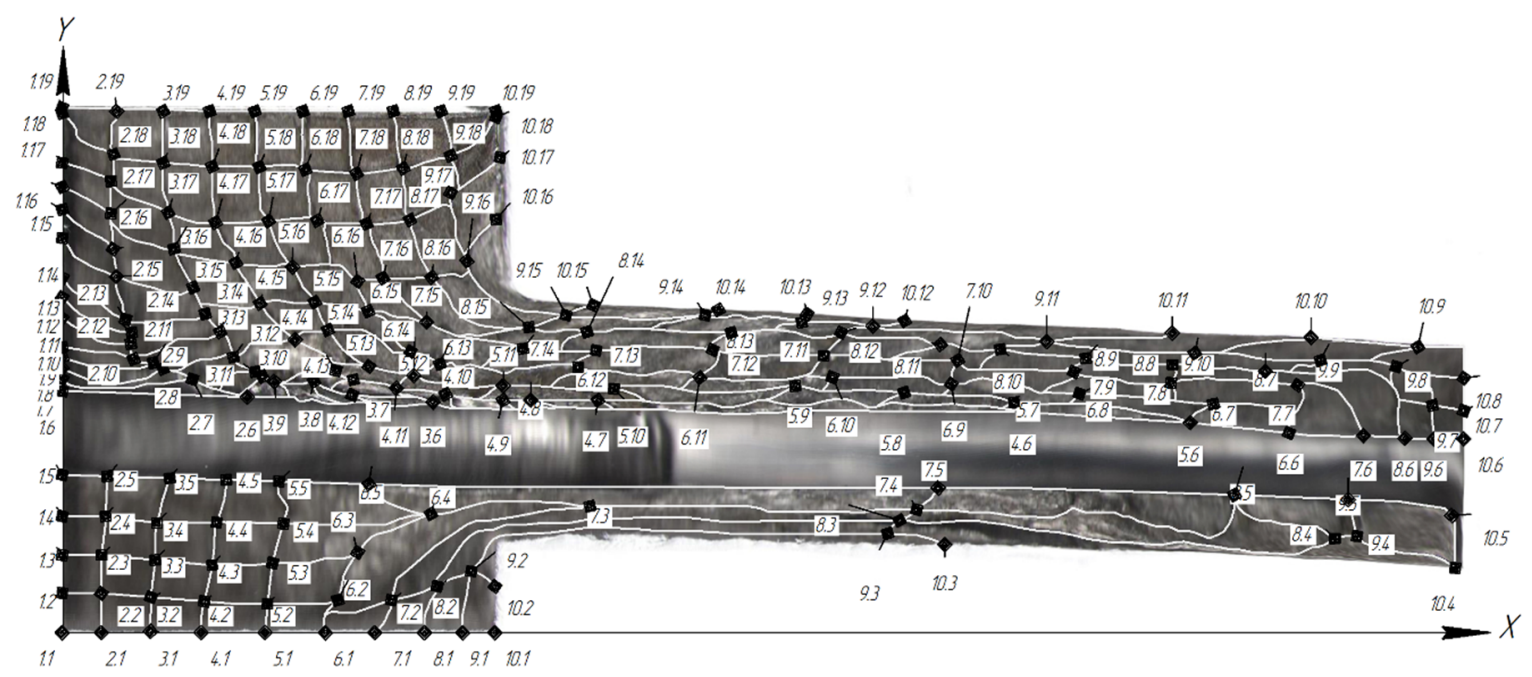

Figure 3. Sample of the pipe $30 \times 10 \mathrm{~mm}$ in size with coordinate grid

Table 3. Coordinates of the grid points of sample pipe in a steady stage: point number (x; y), mm (see Figure 3)

\begin{tabular}{|c|c|c|c|c|c|c|c|c|c|}
\hline 0) & 0) & & ) & 0) & 0) & 0) & 0) & 0) & $5,0 ; 0)$ \\
\hline $1.2(0 ; 4,1)$ & $2.2(4,07 ; 4,09)$ & $3.2(9,23 ; 3,7)$ & $4.2(14,76 ;$ & $5.2(21,34 ; 3)$ & $2(28,66 ; 3,4)$ & $2(34,2 ; 3,4)$ & $2(39,0 ; 4,8)$ & $9.2(42,52 ; 6,37)$ & $10.2(45,0 ; 4,8)$ \\
\hline $1.3(0 ; 8,05)$ & $(4,11 ; 8,05)$ & $(9,66 ; 7,53)$ & $(15,6 ; 7,0)$ & $3(21,87 ; 7,22)$ & $3(30,73 ; 8.3)$ & $3(54,86 ; 13,1)$ & $3(87,04 ; 11,64)$ & $9.3(85,8 ; 10,27)$ & $5 ; 9,14)$ \\
\hline $1.5(0 ; 16,34)$ & $(4,7 ; 16,2)$ & $3.5(1$ & $4.5(17,0$ & $5.5(22,53 ; 15,68)$ & $6.5(31,88 ; 15,4)$ & $7.5(91,07 ; 15)$ & $5(121,8 ; 14,3)$ & $9.5(133,7 ; 13,8)$ & $10.5(144,5 ; 12,15)$ \\
\hline $1.6(0 ; 25,02)$ & $2.6(19,25 ; 24,45)$ & $6(38,56 ; 23,89)$ & $4.6(99,88 ; 22,9)$ & $5.6(117,3 ; 21,78)$ & $6.6(127,7 ; 20,7)$ & $7.6(135,3 ; 20,42)$ & $8.6(139,6 ; 20,16)$ & $9.6(142,6 ; 20,1)$ & $10.6(145,7 ; 20,1)$ \\
\hline $1.9(0 ; 28,51)$ & $(9,5 ; 28,0)$ & $3.9(22,04 ; 26,03)$ & $4.9(45,83 ; 24,1)$ & $5.9(76,2 ; 25,57)$ & $6.9(92,4 ; 25,76)$ & $7.9(105,17 ; 27)$ & $8.9(106,4 ; 28,44)$ & $9.9(130,8 ; 28,2)$ & $10.9(140,9 ; 29,6)$ \\
\hline $1.10(0)-x)$ & 283 & $26,53)$ & $4.10(39,86 ; 24,7)$ & ;25,3) & 5) & 7.10 & 8.1 & 9) & 10.1 \\
\hline 2,64) & ; 30,0$)$ & $0,13)$ & $4 ; 25,3)$ & $5.11(45,84 ; 25,6)$ & $6.11(66,3 ; 26,44)$ & $7.11(79,16 ; 28,7)$ & $8.11(91,3 ; 29,9$ & $9.11(102,4 ; 30,2)$ & $10.11(115,4 ; 31$ \\
\hline $1.12(0 ; 34,8)$ & $2.12(7,23 ; 31,1)$ & $3.12(17,74 ; 28,9)$ & $4.12(30,3 ; 26,2)$ & $5.12(36,56 ; 26,6)$ & $6.12(53,64 ; 27,5)$ & $7.12(68,3 ; 29,15)$ & $8.12(81 ; 31,1)$ & $9.12(84,3 ; 31,76)$ & $10.12(87,57 ; 32,3)$ \\
\hline $1.16(0 ; 46,21)$ & $2.16(5,1 ; 4$ & $3.16(11,6$ & $4.16(18$ & $5.16(23,9 ; 37,9)$ & $6.16(3$ & $7.16(3$ & $8.16(38$, & $9.16(42,0 ; 45,6)$ & $10.16(45,0 ; 42$ \\
\hline $1.17(0 ; 48,7)$ & $2.17(5,06 ; 46,8)$ & $3.17(11,0 ; 43,54)$ & $4.17(15,9 ; 42,5)$ & $5.17(21,46 ; 42,7)$ & $6.17(26,5 ; 42$ & $7.17(31,65 ; 42,4)$ & $8.17(36,16 ; 42,8)$ & $9.17(40,37 ; 45,6)$ & $10.17(45,0 ; 48,67)$ \\
\hline $1.18(0 ; 53,84)$ & $18(5,33 ; 49,6)$ & $3.18(10,5 ; 48,7)$ & $4.18(15,6 ; 48,32)$ & $5.18(20,5 ; 48,25)$ & $6.18(25,28 ; 48,0)$ & $7.18(30,6 ; 47,6)$ & $8.18(35,45 ; 48,1)$ & $9.18(40,37 ; 49,4)$ & $10.18(45,0 ; 53,4)$ \\
\hline $1.19(0 ; 54,0)$ & $19(5,43 ; 54,0)$ & $3.19(10,5 ; 54,0)$ & $4.19(15,3 ;$ & $19(20,0 ; 54,0)$ & $6.19(25,0 ; 54,0)$ & $7.19(29,74 ; 54,0)$ & $8.19(34,44 ; 54,0)$ & $9.19(39,4 ; 54,0)$ & $10.19(45,0 ; 54,0)$ \\
\hline
\end{tabular}

\section{Discussion}

When examining the coordinate grids (see Figures 2, $b, 3$ ), we can draw the following conclusions:

- the assumption of the heterogeneity of strains in the process of pipe extrusion with lateral flow, indicated in (Perlin, 1964; Prozorov, 1969; Thomsen, Yang, \& Kobayashi, 1969; Kosmatskiy, 2016; Kosmatskiy, 2016), is correct;

- the concentration of the strain zone is observed in the part of the sample billet located above the mandrel, while the metal flow picture near the contact surface with the mandrel is characterized by the pitch point of the transverse bands of the coordinate grid;

- near the contact surface of the strained metal with the mandrel and the inlet matrix hole, the cells are subjected to greater strain to a nearer value, in comparison with the zone of the opposite surface of the container, in which the strain is much smaller;

- the bottom part of the sample billet located in the container, and especially on the side opposite to the matrix hole, is represented by small strains, which, on the one hand, proves the correctness of the determination of the stagnant zones of the metal in the process of mathematical modeling (Kosmatskiy \& Fokin, 2015; Kosmatskiy, 2016; Kosmatskiy, 2016), and, on the other hand, affects the formation of the non-uniform thickness of the pipe 
sample. Thus, as shown in Alushkaev, Kosmatskiy, and Shumeiko (2016), in case of realization of the method of pipe extrusion with lateral flow combined with reduction (Kosmatskiy, Vydrin, \& Khramkov, n.d.a), when creating certain conditions of inter-cell tension, it is possible to eliminate the present imperfection;

- the lower part of the longitudinal section of the sample pipe, which is noticeably different in the strain impact on a much larger value in comparison with the upper part, is characterized by an inadequate and hardly reproducible mapping of the coordinate grid. In connection with this, the use of the MCG (Kargin \& Kargin, 2011; Del \& Novikov, 1979) is unacceptable when there are large values of the strain degrees, which also conforms to the results of Kosmatskiy (2016).

The forming work $\left(A_{\Phi}\right)$ can be found:

$$
A_{\Phi}=\sigma_{S} \iiint_{\mathrm{V}} \varepsilon_{H} d V
$$

where $\sigma_{S}$ is the value of the metal resistance of plastic shear strain; $\varepsilon_{U}$ is the intensity of strain; $V$ is the volume of the metal in which the strain takes place.

The intensity of strain $\left(\varepsilon_{U}\right)$ is calculated by the formula (Kolmogorov, 1986):

$$
\varepsilon_{H}=\frac{\sqrt{2}}{3} \sqrt{\left(\varepsilon_{x}-\varepsilon_{y}\right)^{2}+\left(\varepsilon_{y}-\varepsilon_{z}\right)^{2}+\left(\varepsilon_{z}-\varepsilon_{x}\right)^{2}+\frac{3}{2}\left(\gamma_{x y}^{2}+\gamma_{y z}^{2}+\gamma_{z x}^{2}\right)},
$$

where $\varepsilon_{x}, \varepsilon_{y}, \varepsilon_{z}$ are normal component of the strain intensity; $\gamma$ is the tangential component of the strain intensity.

In case of the extrusion with metal lateral flow, an inhomogeneous plastic flow is also observed (Kosmatskiy, 2016), and the magnitude of the strain intensity is different at different points of the strain zone. Therefore, to determine the forming work, it is necessary to determine the intensity of strain (2) as a function, the volumetric integral of which can be used to calculate the forming work. The analytical definition of the strain field is difficult. And the MCG is used in order to determine the field of strain (Kargin \& Kargin, 2011; Del \& Novikov, 1979).

To find the strain intensity, it is necessary to determine the components of the strain tensor. It is known from the theory of plasticity (Thomsen, Yang, \& Kobayashi, 1969; Kolmogorov, 1986) that:

$$
\left\{\begin{array}{l}
\varepsilon_{x}=\frac{\partial u_{x}}{\partial x} \\
\varepsilon_{y}=\frac{\partial u_{y}}{\partial y} \\
\varepsilon_{z}=\frac{\partial u_{z}}{\partial z} \\
\gamma_{x y}=\frac{\partial u_{x}}{\partial y}+\frac{\partial u_{y}}{\partial x} \\
\gamma_{y z}=\frac{\partial u_{y}}{\partial z}+\frac{\partial u_{z}}{\partial y} \\
\gamma_{x z}=\frac{\partial u_{z}}{\partial x}+\frac{\partial u_{x}}{\partial z}
\end{array}\right.
$$

where $u$ is the displacement of an elementary volume.

It is important to mention that the hypothesis that describes the trajectory of the metal flow was put forward at the stage of preparation for the experimental study, as shown in (Kosmatskiy \& Fokin, 2015; Kosmatskiy, 2016). 
Based on the assumption that the strain reaches the highest values in the chosen plane (see Figures 2, 3), a study of the nature of the metal flow was carried out on this very purpose. The present assumption undoubtedly simplifies the problem of the mathematical description of the metal forming, but in the first approximation it can be considered admissible for description. Thus, the above assumption is characterized by the following inequalities of shear deformations: $\gamma_{y z}<\gamma_{x y}, \gamma_{z x}<\gamma_{x y}$, which are impossible to compute. However, to take them into account, the corresponding equality condition is taken: $\gamma_{v y}=\gamma_{1 z}=\gamma_{x x}$. At the same time, it is obvious that the estimate of the magnitude of the strain intensity will be exaggerated, which must be taken into account in the further formulation of the conclusions.

Thus, a preliminary evaluation of possible metal flow pictures for the pipe extrusion process with lateral flow suggests a corresponding estimation of the degree of strain:

$$
\left\{\begin{array}{l}
\varepsilon_{x}=\frac{\partial u_{x}}{\partial x} \\
\varepsilon_{y}=\frac{\partial u_{y}}{\partial y} \\
\varepsilon_{z}=1-\varepsilon_{x}-\varepsilon_{y} \\
\gamma_{x y}=\frac{\partial u_{x}}{\partial y}+\frac{\partial u_{y}}{\partial x} \\
\gamma_{y z}=0 \\
\gamma_{z x}=0
\end{array}\right.
$$

To determine the elements of the strain intensity it is necessary to define the coordinates of all the points before $\left(x_{i j}^{\text {нач }}, y_{i j}^{\text {нач }}\right)$ and after the strain $\left(x_{i j}, y_{i j}\right)$. Then it is possible to find an average value of the height $(H)$, width $(S)$ and volumes $(V)$ of the cells, respectively (Kosmatskiy, 2016):

$$
\begin{aligned}
& H_{i, j}=\frac{y_{i+1, j}-y_{i, j}+y_{i+1, j+1}-y_{i, j+1}}{2} ; \\
& S_{i, j}=\frac{x_{i, j}-x_{i, j+1}+x_{i+1, j}-x_{i+1, j+1}}{2} ; \\
& V_{i, j}=\pi S_{i, j}\left(2 \cdot\left|x_{i, j}^{\text {Hau }}-d_{\text {Кон }}\right|-S_{i, j}\right) .
\end{aligned}
$$

where $d_{\text {Кон }}$ is the container diameter.

$\underline{W}$ e shall define the values of four angles for each cell $\left(\varphi_{i, j, k}\right)$. We find the angles between the vectors $\vec{a}$ and $\vec{b}$ by the following formula, where $k$ is the number of the angle in the cell:

$$
\varphi=\arccos \left(\frac{x_{a} x_{b}+y_{a} y_{b}}{|\vec{a}| \cdot|\vec{b}|}\right)
$$

The scheme for determining the values, reflected in the formulas (5-7), is shown in Figure 4. 


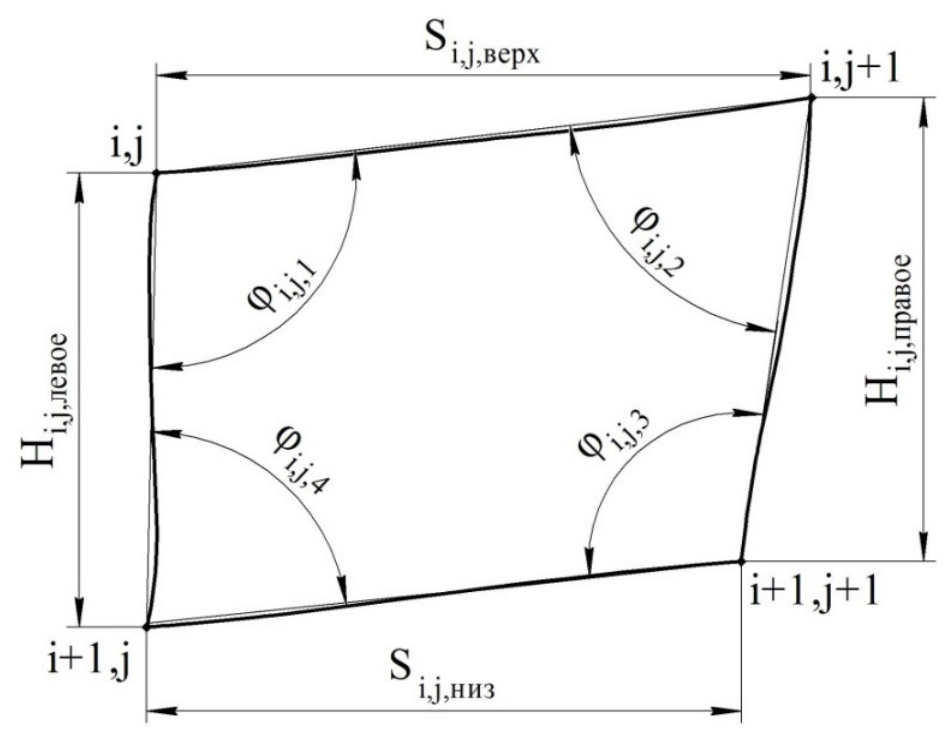

Figure 4. Computational scheme of the strain cell

In accordance with Figure 4, the height of the cells can be determined by the formula:

$$
H_{i, j}=\frac{H_{i, j, \text { Левое }}+H_{i, j, \text { Правое }}}{2},
$$

where $H_{i, j, \text { Левое }}=y_{i+1, j}-y_{i, j}, H_{i, j, \text { Правое }}=y_{i+1, j+1}-y_{i, j+1}$.

The width of the cells, in accordance with Figure 4, can be found as follows:

$$
S_{i, j}=\frac{S_{i, j, \text { Верх }}+S_{i, j, \text { Низ }}}{2},
$$

where $S_{i, j, \text { Верх }}=x_{i, j+1}-x_{i, j}, S_{i, j, \text { Низ }}=x_{i+1, j+1}-x_{i+1, j}$.

Further we find the degrees of strain:

$$
\left\{\begin{array}{l}
\varepsilon_{x}=\ln \left(\frac{S_{i j}}{S_{0 i j}}\right) \\
\varepsilon_{y}=\ln \left(\frac{H_{i j}}{H_{0 i j}}\right) \\
\gamma_{x y}=\frac{\ln \left(\sqrt{\frac{\varphi_{i, j, 1} \varphi_{i, j, 3}}{\varphi_{0 i, j, 1} \varphi_{0 i, j, 3}}}\right)+\ln \left(\sqrt{\frac{\varphi_{i, j, 2} \varphi_{i, j, 4}}{\varphi_{0 i, j, 2} \varphi_{0 i, j, 4}}}\right)}{2}
\end{array} .\right.
$$

After that, using the dependence (2), the intensity of strain ( $\left.\varepsilon_{U}\right)$ is determined.

Thus, knowing the information on the intensity of strain, it is possible to determine the forming work in the process of pipe extrusion with lateral flow in each cell: 


$$
A_{\Phi}=\pi \sigma_{S} \cdot \varepsilon_{U i, j} \cdot V_{i, j} .
$$

Using the results of measurements of the coordinate nodes of the grid presented in Tables $1-3$, the calculation of forming work is performed for pipe extrusion with lateral flow of $30 \times 10 \mathrm{~mm}$ in size made of lead C1, corresponding to certain phases of the process: sample billet pressing-out is $0.301 \mathrm{~kJ}$ and the steady process of sample pipe extrusion is $0.498 \mathrm{~kJ}$.

Thus, the conducted experimental study of the sample pipe extrusion process with lateral metal flow when using the MCG (Kargin \& Kargin, 2011; Del \& Novikov, 1979) allows drawing the following conclusions:

- in comparison with direct metal flow (Kosmatskiy, 2016), the considered variety of pipe extrusion process with lateral metal flow differs in the following features: axial asymmetry of strains and increased unevenness of the strains due to this fact.

- accepted in the mathematical modeling (Kosmatskiy \& Fokin, 2015; Kosmatskiy, 2016) assumptions about the location of metal stagnant zones are correct. Thus, the part of the strained billet located in the bottom part of the container is predominantly below the matrix, and the part which is remote from it by the amount up to $0,5 \cdot d_{\text {Кон }}$ is strained insignificantly (see Figures $2, b, 3$ ).

- the pipe length distribution of coordinate grid (see Figure 3) differs in heterogeneity. The front part of the sample pipe is not fully worked out along the thickness of the wall. The rear part is characterized by a dense grid structure. At the same time, the distribution of the grid along the thickness of the wall of the sample pipe, which is conditional upon the presence of a stagnant zone, indicated in point 2, preserves the heredity of this section and forms the corresponding uneven distribution of the longitudinal and transverse bands of the coordinate grid directly in the lower part of the plane under consideration.

- the drawn conclusions (points 1-3) allow one to implicitly consider the presence of anisotropy of the properties by the body of the sample pipes manufactured using the method of extrusion with lateral flow. Thus, in order to create favorable conditions for the strained metal flow in the extrusion process with lateral flow, it seems rational to use a bilateral pressing scheme (Perlin, 1964; Perlin \& Reithbarg, 1975), which will eliminate the metal stagnant zone in the bottom of the container (see Figures $2, b, 3$ ) and, accordingly, will ensure the homogeneity of the grid distribution along the thickness of the wall of the sample pipe.

In conclusion, it should be mentioned that if dynamic and plastic similarity is observed (Chizhikov, 1970), it is possible to apply the results of the experimental study using the MCG (Kargin \& Kargin, 2011; Del \& Novikov, 1979) under industrial conditions, when designing the appropriate pressing equipment.

\section{References}

Alushkaev, E. A., Kosmatskiy, Y. I., \& Shumeiko, V. P. (2016). Evaluation of the possibility of increasing the accuracy of the geometric dimensions of pipes due to the combination of lateral pressing and reduction processes. Chelyabinsk: Bulletin of SUSU.

Chizhikov, Y. M. (1970). The theory of similarity and simulation of metal forming processes (p. 296). Moscow: Metallurgy.

Del, G. D., \& Novikov, N. A. (1979). The method of grade grid (p. 144). Moscow: Mechanical Engineering.

Kargin, V. R., \& Kargin, B. V. (2011). The basics of technological processes of metal treatment under pressure: Extrusion Unit: textbook (p. 104). Samara: Publishing House of Samara State University.

Kolmogorov, V. L. (1986). Mechanics of metal forming treatment (p. 688). Moscow: Metallurgy.

Kosmatskiy, Y. I. (2016). Experimental study of the pipe extrusion process using the method of coordinate grids. Bulletin of technical and economic information (Ferrous Metallurgy), 12(1404), 75-82.

Kosmatskiy, Y. I. (2016). Modeling of the process of transverse lateral pressing using the apparatus for pressing out the butt end (pp. 221-229). Scientific search: materials of the eighth scientific conference of post-graduate students and doctoral students. Technical sciences.

Kosmatskiy, Y. I. (2016). The main directions of research in the field of improving the theory, technology and equipment of pipe-press systems. Magnitogorsk: Bulletin of MSTU named after G.I. Nosov.

Kosmatskiy, Y. I., \& Fokin, N.V. (2015). Mathematical modeling of combined process of casting and lateral pressing. Chelyabinsk: Bulletin of SUSU. 
Kosmatskiy, Y. I., Khramkov, E. V., \& Fokin, N. V. (2013). Improvement of the ways of pipe production using the combined process. Proceedings of the $4^{\text {th }}$ International Academic Conference (November 29-30, 2013. V. 1, pp. 203-205). Applied and Fundamental Studies. St. Louis, Missouri, USA: Publishing House «Science and Innovation Center».

Kosmatskiy, Y. I., Vydrin, A. V., \& Khramkov, E. A. (n.d.a). Pat. 143437. Apparatus for obtaining hollow shapes (app. 12.03.14, publ. 20.07.14, bul. no. 20, 10 p.).

Kosmatskiy, Y. I., Vydrin, A. V., \& Khramkov, E. A. (n.d.b). Pat. 144990. Apparatus for obtaining hollow shapes (app. 05.07.14, publ. 10.09.14, bul. no. 25, 9 p).

Perlin, I. L, \& Reithbarg, L. H. (1975). The theory of metal pressing (2nd ed., pp. 17-19). Moscow: Metallurgy.

Perlin, I. L. (1964). Theory of metal pressing (p. 423). Moscow: Metallurgy.

Prozorov, L. V. (1969). Pressing of steel and refractory alloys (pp. 8-20). Moscow: Mechanical Engineering.

Thomsen, E., Yang, C., \& Kobayashi, S. (1969). Mechanics of plastic deformation in metal processing (pp. 287-292). Moscow: Mechanical Engineering.

Vydrin, V. N. (1959). Deformation of hollow cylindrical bodies (pp. 48-51). Scientific reports of the higher school. Moscow: Metallurgy.

\section{Copyrights}

Copyright for this article is retained by the author(s), with first publication rights granted to the journal.

This is an open-access article distributed under the terms and conditions of the Creative Commons Attribution license (http://creativecommons.org/licenses/by/4.0/). 